\title{
A Comparison of Vibrotactile Thresholds on the Finger Obtained with ISO type Equipment and Japanese Equipment
}

\author{
Setsuo MAEDA ${ }^{1 *}$, Miyuki MORIOKA ${ }^{1}$, Yoshiharu YONEKAWA ${ }^{2}$, \\ Kazuo KANADA ${ }^{2}$ and Yukio TAKAHASHI ${ }^{2}$
}

\author{
${ }^{1}$ Human Factors Research Unit, Department of Industrial Engineering, Faculty of Science and Technology, Kinki \\ University, Kowakae, 3-4-1, Higashiosaka, Osaka 577, Japan \\ ${ }^{2}$ National Institute of Industrial Health, 21-1, Nagao 6-chome, Tama-ku, Kawasaki 214, Japan
}

Received April 4, 1997 and accepted May 15, 1997

\begin{abstract}
A vibrotactile threshold measurement system that enables the thresholds at the fingertips to be determined more rapidly and precisely has been developed. This system was studied to assess the impact of various factors on the obtained values. An experiment using two different types of equipment was also conducted to assess the repeatability of measurement. One system was similar to that required by International Standard (System A), and the other system was of the currently used in Japan (System B). The subjects were nine males and one female, measurements were taken on three different days. This paper compares the structure of the equipment used internationally (ISO/CD13091) and the equipment typically used in Japan and the measurements of vibrotactile thresholds taken at a $125 \mathrm{~Hz}$ frequency using Systems $A$ and B. The measurement method and conditions adopted were almost the same as those outlined in the ISO draft. The results of this experiment showed that there were some differences between the two systems. The vibrotactile thresholds measured using System B showed higher values than did those measured using System A. The results also indicated that equipment that satisfies ISO standards provides sufficient repeatability for use as a diagnostic aid. Also, this paper is shown the vibrotactile measurement equipment conditions must be considered when using vibrotactile threshold measurement equipment in Japan.
\end{abstract}

Key words: Vibration, Thresholds, Repeatability, Diagnosis, Finger

\section{Introduction}

Peripheral neuropathies in the upper extremities, which may occur as a result of occupational exposure to handtransmitted vibrations. These diseases may cause a variety of disorders of the fingers, hands and arms.

Neurological disturbances and vascular disorders (known as Raynaud's phenomenon or vibration-induced white finger) are important symptoms of the vibration syndrome ${ }^{1)}$. Fingertip vibrotactile thresholds have been used to quantify the

*To whom correspondence should be addressed. neuropathy produced by hand-transmitted vibrations ${ }^{2-6)}$. Vibrotactile thresholds have also been used to estimate the acute physiological effects of hand-transmitted vibration exposure on the sensory system, and to investigate the permissible limits of occupational exposure to vibrations. Many studies have related temporary threshold shifts (TTS) in vibratory sensations to the severity of vibration exposure ${ }^{7-18}$. Vibration sense thresholds at the fingertips are sometimes used to evaluate the neuropathy, and the vibrotactile thresholds on the fingers are known to depend on these specifies, measuring equipment, procedure, and method or algorithm. Researchers around the world ${ }^{19)}$ have used many different types of vibrotactile 
measurement equipment.

Since 1991 The Working Group 8 (Vibrotactile Perception) of ISO/TC108/SC4 has been involved in optimizing testing procedures and interpreting virotactile perception thresholds. Although the Committee Draft International Standard ISO/ CD $13091^{20)}$ has been proposed by ISO/TC108/SC4/WG8 unlike audiometers standards, the measuring equipment and measuring algorithms for vibrotactile thresholds have not yet been agreed upon internationally. Therefore, few researchers have been considered the measuring equipment and measuring algorithms by using commercially available vibrometers ${ }^{19,21-23}$. From these results, they found that all vibrotactile threshold determinations should take into account the frequency of vibrations, the area of contact with vibrations, the conditions around the contact area, the contact force, the push force, and the finger temperature.

In Japan, only one type of equipment has been used as a diagnostic aid. This equipment is manufactured by a Japanese company. However, the differences between the vibrotactile threshold values obtained by using ISO/CD 13091 equipment and those obtained by using the Japanese equipment are not yet understood in Japan.

This paper compares the structure of equipment that satisfies international standards (ISO/CD13091) with that of equipment made in Japan, based on measurements of vibrotactile thresholds obtained by using two systems, that is, equipment manufactured in accordance with the International Standard (System A) and equipment manufactured in Japan(System B). Then, this paper assesses the vibrotactile thresholds values and repeatability of each system, and shows the necessary conditions for taking vibrotactile threshold measurements on fingertips using the vibrotactile threshold measurement equipment manufactured in Japan.

\section{Comparison between ISO Draft Equipment and Japanese Equipment}

A comparison of ISO/CD 13091 equipment and the Japanese equipment is shown in Table 1. As Table 1 shows, ISO/CD 13091 equipment can measure vibrotactile thresholds using three kinds of Mechanoreceptors, SA I, FA I, and FAII, which have frequencies of 4,25 , and $125 \mathrm{~Hz}$, respectively. Also, the following conditions are defined by ISO/CD 13091; the contact area is $4.0 \pm 2.0 \mathrm{~mm}$ in diameter, the contact force is $0.1 \pm 0.05 \mathrm{~N}$, the surround of type $A$ is a directly controlled probe-skin contact force controlled directly, the surround of type $B$ is a $1.5 \pm 0.5 \mathrm{~mm}$ probesurround gap, the surround-fingertip force of type $B$ is $<0.5$ $\mathrm{N}$, and the measuring algorithm is the up-down method. ISO/ CD 13091 equipment can measure the acceleration of the thresholds, unlike the Japanese equipment which cannot measure the acceleration of the vibrotactile thresholds at

Table 1. Comparison of the ISO/CD 13091 and the Japanese equipment

\begin{tabular}{|c|c|c|}
\hline Contents & ISO/CD 13091 & Japanese equipment \\
\hline Mechanoreceptor & SA I, FA I, FA II & FA II \\
\hline Frequency $(\mathrm{Hz})$ & $4.0,25,125 \mathrm{~Hz}$ & $63,125,250 \mathrm{~Hz}$ \\
\hline Measurement method & Automatic & Manual \\
\hline Stimulation & intermittent $(3.1-160 \mathrm{~Hz})$ & intermittent and continuous \\
\hline Support & $\begin{array}{l}\text { full length of forearm, hand and } \\
\text { finger, seat with back rest }\end{array}$ & none \\
\hline Skin temperature & $26-36^{\circ} \mathrm{C}$ & none \\
\hline Room temperature & $20-30^{\circ} \mathrm{C}$ & none \\
\hline Contact area & $4.0 \pm 2.0 \mathrm{~mm}$ diameter & $15 \mathrm{~mm}$ diameter \\
\hline Contact force & $0.1 \pm 0.05 \mathrm{~N}$ & none \\
\hline Surround type A & probe-skin contact force, controlled directly & - \\
\hline Surround type B push force & $\begin{array}{l}1.5 \pm 0.5 \mathrm{~mm} \text { probe-surround gap, } \\
<0.5 \mathrm{~N} \text { surround-fingertip force }\end{array}$ & - \\
\hline Measurement algorithm & up-down method & method of adjustment \\
\hline Calibration & mandatory & - \\
\hline Safety & the requirement IEC $601-1$ & - \\
\hline Vibrotactile thresholds report & $\mathrm{ms}^{-2}$ r.m.s. or $\mathrm{dB}\left(\mathrm{re}: 10^{-6} \mathrm{~ms}^{-2}\right)$ & $\mathrm{dB}\left(\mathrm{re}: 10^{-5} \mathrm{~ms}^{-2}\right)$ \\
\hline
\end{tabular}


the fingertips directly. Moreover the Japanese equipment cannot measure the SAI and FA I mecanoreceptor effect and also does not mention the method used to support the arm and finger, the contact force, the push force, and the method used to calibrate the acceleration of the contact probe. There are many differences between the ISO/CD 13091 equipment and the Japanese equipment. There are no commercially available vibrometers that satisfies ISO/CD 13091 standard anywhere in the world. However, Maeda and Griffin used ISO-type equipment that could control the push force, the contact force, and the surround. Although the Japanese equipment is different from the equipment used by Maeda and Griffin ${ }^{19}$, ISO/CD 13091 type B equipment and the Japanese equipment have vibrations applied in the same direction. From the results obtained by Maeda and Griffin $^{19)}$, ISO-type equipment might be better repeatability than Japanese equipment. However, no vibrotactile threshold data comparing ISO-type equipment and Japanese equipment are available. Therefore, this paper compared the structures of these two types of equipment, and measured the vibrotactile thresholds using two different systems: equipment that satisfies International Standard (System A) and equipment manufactured in Japan (System B).

\section{Experiment}

\section{Equipment}

Two different systems were used in this experiment. "System A" was similar of the equipment proposed ISO draft standards. "System B" was equipment manufactured in Japan.

System A: Although the contact force, push force, and surrounding effects have been demonstrated by Maeda and Griffin $^{23)}$, as well as Harada and Griffin ${ }^{9)}$, the effects of a contact force of $0.1 \pm 0.05 \mathrm{~N}$ of and a surround fingertip force of $<0.5 \mathrm{~N}$ as defined by ISO/CD 13091 are not yet understood. Also, there is no commercially available equipment that completely satisfies ISO/CD 13091 characteristics. Therefore, this experiment used a commercially available vibrometer. The system provides computer-controlled measurement of tactile thresholds for vibration stimuli. It consists of a vibrometer and a force meter, as shown in Figure 1. The vibrometer houses a vibrator, which is mounted on a counterbalance to provide a constant upward contact force between the probe and the subject's finger. A sliding counterweight allows this force to be adjusted, if necessary. An accelerometer is mounted on the vibrator, with the contact probe attached to its upper surface. The probe, which has a flat circular end with a diameter of $6 \mathrm{~mm}$, protrudes through a hole of $10 \mathrm{~mm}$ in diameter in a plastic plate. This plate is fitted with strain gauges to monitor and control the pushing force from the finger. The vibrometer also houses the electronics for conditioning the accelerometer and strain gauge output signals and a power amplifier for driving the vibrator. A pre-determined set of selected vibration frequencies (in a range 16 to $500 \mathrm{~Hz}$ ) is automatically presented. The acceleration magnitude corresponding to the vibrotactile threshold at each frequency is computed after the completion of each test using the procedures defined in BS $6655^{24)}$ and ISO $6189^{25}$. The vibrotactile thresholds are then averaged, and a mean is taken. This vibrotactile threshold mean represents the average peak and the average trough. Standard deviations are also computed by using the square root of the mean variance of the peaks and troughs. In this experiment, the vibration magnitude is controlled by a computer (HP85F) which generates vibration signals that are sent to the Function Synthesizer (NF 1915). The synthesizer sends the signals received from the computer to the vibrator and oscilloscope. System A uses units of $\mathrm{ms}^{-2} \mathrm{rms}$. These acceleration signals are preset at $2.5 \mathrm{~dB}$.

System B: The Japanese equipment has been manufactured by the same company since 1975 , and since then has been used as a diagnostic aid to measure the threshold. This system consists of a vibration exciter with a $15 \mathrm{~mm}$ diameter vibration tip with a flat surface, and a vibration amplitude and frequency controller, as shown in Figure 2. It has width of $450 \mathrm{~mm}$, a depth of $220 \mathrm{~mm}$, a height of $110 \mathrm{~mm}$ and a weight of $5 \mathrm{~kg}$. A vibration tip mounted on the vibration exciter generates vibrations. A controller maintains the vibration frequencies at 63,125 , and $250 \mathrm{~Hz}$ and the vibration amplitude at $2.5 \mathrm{~dB}$.

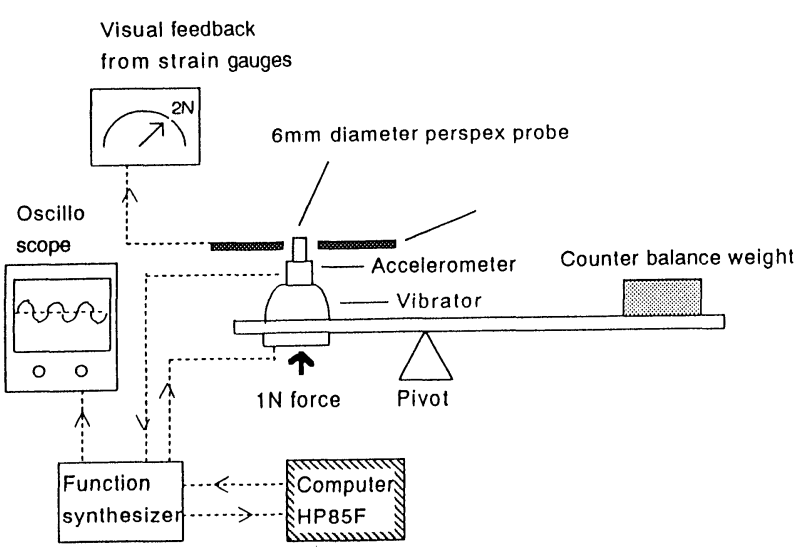

Fig. 1. Vibrotactile measurement equipment of System A (ISOtype equipment) 


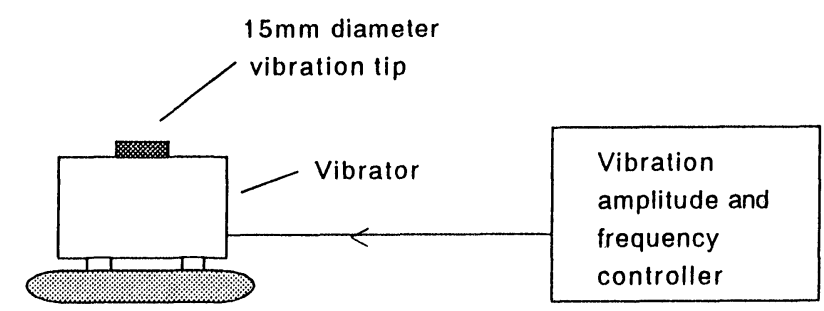

Table 2. Physical characteristics of 10 subjects

\begin{tabular}{lcc}
\hline & mean & SD \\
\hline weight $(\mathrm{kg})$ & 61.6 & 10.9 \\
height $(\mathrm{cm})$ & 170.3 & 6.96 \\
age & 21.6 & 0.52 \\
sex & 9 males and 1 female
\end{tabular}

Fig. 2. Japanese vibrotactile measurement equipment (System B)

Table 3. Experimental conditions of System A and System B

\begin{tabular}{|c|c|c|}
\hline & System A & System B \\
\hline Contact area & $6 \mathrm{~mm}$ diameter & $15 \mathrm{~mm}$ diameter \\
\hline Surrounding & $10 \mathrm{~mm}$ diameter & None \\
\hline Finger push force & $2 \mathrm{~N}$ & $\begin{array}{l}\text { None: The patient touches } \\
\text { lightly on the test tip. }\end{array}$ \\
\hline Probe contact force & $1 \mathrm{~N}$ & $\begin{array}{l}\text { None: The patient should } \\
\text { find the area of greatest sensitivity }\end{array}$ \\
\hline Vibration frequency & \multicolumn{2}{|c|}{$125 \mathrm{~Hz}$} \\
\hline Measuring method & \multicolumn{2}{|c|}{ UD method } \\
\hline Measuring finger & \multicolumn{2}{|c|}{ The middle finger of right-hand } \\
\hline Level rate & \multicolumn{2}{|c|}{$2.5 \mathrm{~dB}$} \\
\hline Starting level & $70 \mathrm{~dB}$ & $80.5 \mathrm{~dB}$ \\
\hline Room temperature & \multicolumn{2}{|c|}{$22-26^{\circ} \mathrm{C}$} \\
\hline Skin temperature & \multicolumn{2}{|c|}{ Above $23^{\circ} \mathrm{C}$} \\
\hline Measuring days & \multicolumn{2}{|c|}{3 days } \\
\hline Test time & \multicolumn{2}{|c|}{30 seconds/person } \\
\hline
\end{tabular}

Moreover, the controller is calculated to send the acceleration applying for the vibration amplitude. This equipment expresses thresholds in decibels (dB). Therefore, Japanese vibrometers have some problems. For example, the $0 \mathrm{~dB}$ reference is different for each vibrometer ${ }^{22)}$. The reason for such problems is believed that Japanese vibrometers do not measure acceleration when measuring thresholds.

\section{Subjects}

Ten subjects ( 9 males and 1 female) participated in the study. They were healthy students attending the Kinki University with no history of neuromuscular or vascular disorders. None of the subjects had any occupational experience operating hand tools or had ever suffered any serious injuries in the upper extremities. Table 2 gives the physical characteristics of the subjects.

\section{Procedure}

The experiment was performed on three different days, and each subject was measured once a day. Before the experiment, all subjects read the instructions sheet provided in the Appendix. Table 3 shows conditions adopted in this experiment.

First, the right-hand finger temperature was measured, since the skin temperature is known to affect vibrotactile thresholds ${ }^{3}$. This experiment was performed only when the finger temperature was above $23^{\circ} \mathrm{C}$. If the finger temperature was below $23^{\circ} \mathrm{C}$, the subject was asked to rest in a room until the finger temperature was at or above $23^{\circ} \mathrm{C}$. Each subject was seated with their right forearm laid on an armrest, and put the middle finger of the right hand on the vibration tip. The mean and standard deviation (SD) of the finger skin temperature was $30.4^{\circ} \mathrm{C}\left(\mathrm{SD} 0.6^{\circ} \mathrm{C}\right)$. As this table shows, the experimental conditions were almost the same for both System A and B; however, the equipment structures : 1) contact force, 2) push force, 3) contact area, 4) surround were different. With System 


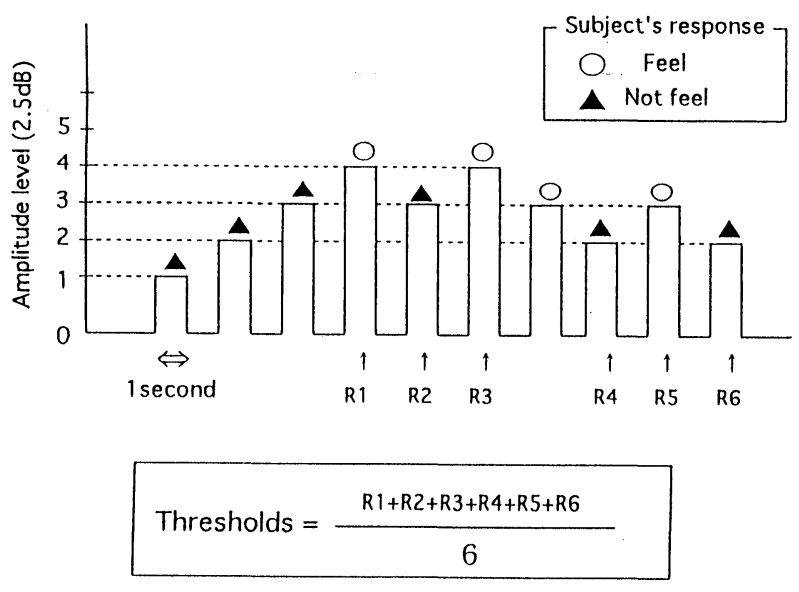

Fig. 3. The experimental measuring pattern of UD method

A the subject watched a meter carefully to maintain his push force at the specified level (2N). With System B the push force was controlled according to each subject as suggested by the system manufacturer.

The UD method ${ }^{26)}$ was used in the experiment as shown in Figure 3. The Up-Down method commonly known as the UD method, is one of the psychophysical algorithms used to make threshold determinations. The UD method is a simple generalization of the most orthodox algorithm for estimating a 50-percent threshold. The level of the test stimulus is varied in steps of a constant size, $2.5 \mathrm{~dB}$ was adopted in this experiment. As indicated above in Figure 3, if a "feel" response was given by the subject, the following stimulus was at the next lowest level, and if a "not feel" response was given, the following stimulus was at the next highest level. This experiment was continued for six turnarounds. The threshold value was determined by the mean value of the peaks and the troughs (R1 to R6). The step size, stimulus starting point, and turnaround numbers have not been standardized for vibrotactile thresholds.

\section{Analytical Methods}

A test was conducted to determine the difference between the means of the vibrotactile threshold obtained from the two systems. Differences between subjects and days were analyzed by using a multifactor variance analysis. Rootmean-square errors and Spearman's correlation coefficients have already been used to assess the repeatability of the two systems ${ }^{19}$. The r.m.s. errors are the square roots of the mean squared differences of the measurements obtained during the three day period.

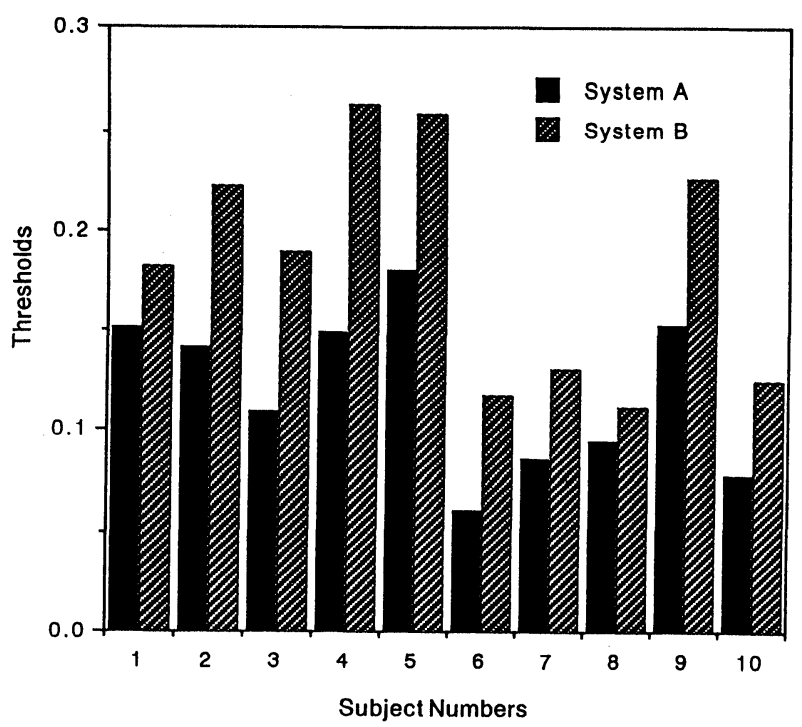

Fig. 4. Comparison of mean thresholds obtained from each subjects There was significant difference $(p<0.05)$ between the two systems.

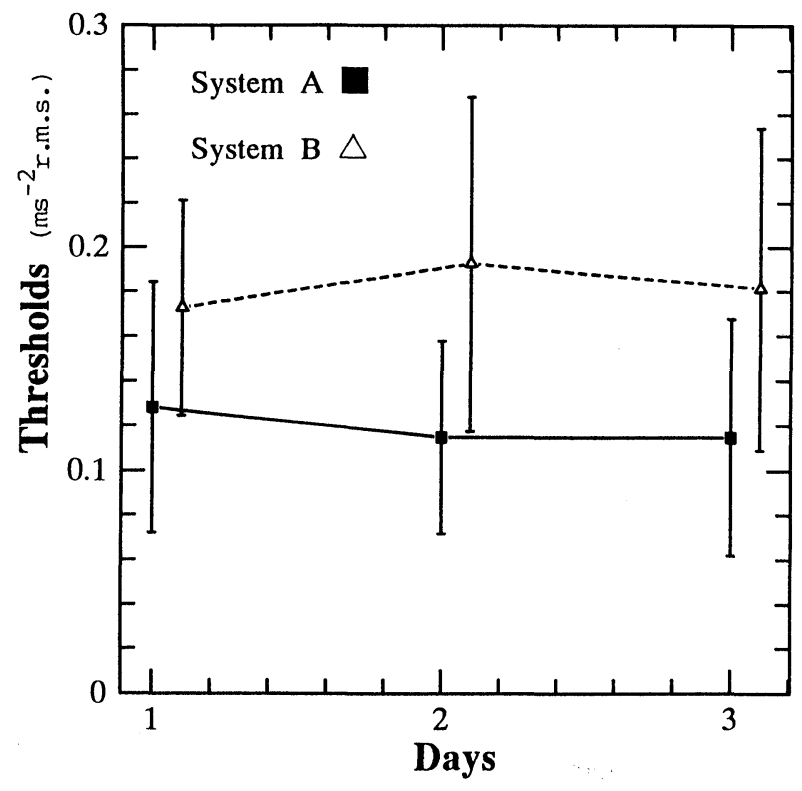

Fig. 5. Comparison of thresholds obtained with different days 10 subjects; mean, standard deviation. There was significant difference $(p<0.01)$ between the two systems.

\section{Results and Discussion}

\section{Comparison of System A and System B}

Figure 4 shows the mean thresholds of each subjects. Figure 5 shows the two system's mean threshold results and the standard deviations obtained on different days. As these 
Table 4. Analysis of variance summary table of System A (ISO type equipment)

\begin{tabular}{llccc}
\hline Factors & Sum squares & Deg. freedom & Mean square & F. ratio \\
\hline A (subjects) & 0.042371 & 9 & 0.0047079 & 2.40 \\
B (days) & 0.0071761 & 2 & 0.00035881 & 0.18 \\
Errors & 0.03525 & 18 & 0.0019585 & \\
Total & 0.078342 & 29 & & \\
\hline
\end{tabular}

Table 5. Analysis of variance summary table of System B (Japanese equipment)

\begin{tabular}{llcll}
\hline Factors & Sum squares & Deg. freedom & Mean square & F. ratio \\
\hline A (subjects) & 0.094301 & 9 & 0.010478 & $5.00 * *$ \\
B (days) & 0.0019629 & 2 & 0.00098146 & 0.47 \\
Errors & 0.037721 & 18 & 0.0020956 & \\
Total & 0.13398 & 29 & & \\
\hline
\end{tabular}

figures show, System B obtained higher mean thresholds values than System $A$ for all subjects. The difference in the means of the two systems was $0.063\left(\mathrm{~ms}^{-2} \mathrm{rms}\right)$, which translate into about $4(\mathrm{~dB})$. A test was conducted to determine the difference between the vibrotactile threshold means of the two systems. This difference was found to be significant $(p<0.05)$. Based on these results, it can be concluded that there is a significant difference between the threshold values obtained by the two systems. The standard deviation values for the System A vibrometer were somewhat smaller than those for the System B vibrometer.

Tables 4 and 5 summarized of the analysis of variance. Variance analysis was adopted to examine the influence of subjects and measuring days on the vibrotactile thresholds determined by each system. There was no significant differences between the results obtained on different days. Table 6 shows the absolute vibrotactile threshold differences between the two systems over the three day period. The differences were calculated based on the $\mathrm{dB}$, taking the values shown in Figure 5. There were no significant differences between the two systems. Table 6 clearly shows that all the absolute values are smaller than $1 \mathrm{~dB}$ for both systems. Although there were no significant differences between the two systems in days, there was a significant difference between subjects in System B as shown in Table 5. Figures 4 and 5 also show that there were differences in the vibrotactile thresholds obtained by System A and System B. Tables 4 and 5 show that there were no differences in days effects between System A and System B. Figure 5 seems to suggest that the variability in the vibrotactile thresholds was lower for System A; however, Tables 4 and
Table 6. The absolute vibrotactile threshold differences between the two systems on three days

\begin{tabular}{ccc}
\hline & System A (dB) & System B (dB) \\
\hline$|(1-2)|$ & 0.62 & 0.94 \\
$|(1-3)|$ & 0.80 & 0.41 \\
$|(2-3)|$ & 0.18 & 0.53 \\
\hline
\end{tabular}

5 do not show that one system was significantly better than the other with regard to repeatability.

\section{Repeatability of System A and System B}

The results of Maeda and Griffin ${ }^{19)}$ and Lindsel1 ${ }^{27)}$ clearly indicate that high repeatability can only be ensured by high correlation coefficients and small r.m.s. errors. Therefore, in this paper, Spearman's correlation coefficients and r.m.s. errors between Systems made in the three days on each System were used to check repeatability, as shown in Figures 6 and 7. For example, a high correlation between thresholds obtained on two different occasions indicates that a subject with a high threshold on one day (relative to the other subjects) had a high threshold on other days (relative to the other subjects). However, if the two sets of results shown in Figure 8 are obtained, the correlation can be high when repeatability is high (i.e., the data for group 1: Day 1 data=Day 2 data), and the correlation can be high when repeatability is not high (as in group 2). It is therefore possible to have the same correlation coefficient even though repeatability is higher in group 1 than in group 2 . Repeatability was 


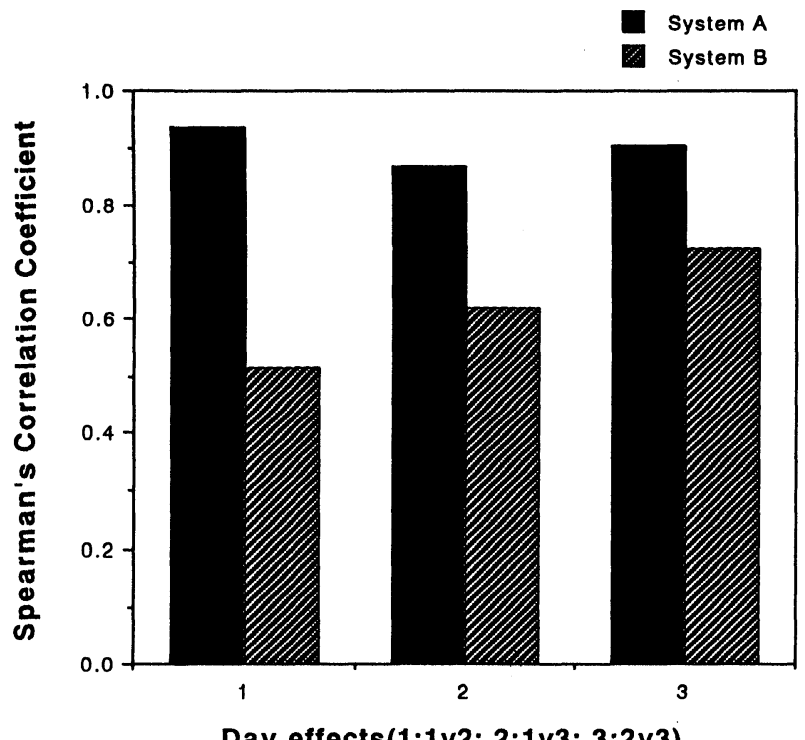

Fig. 6. The Spearman's correlation coefficients on the three days There was significant difference $(p<0.05)$ between the two systems.

quantified in terms of the square root of the sum of the squared differences between a $45^{\circ}$ slope line (in Fig. 8 ) and the experimental data (i.e., r.m.s. errors). To ensure high repeatability there should be a high correlation coefficient and small r.m.s. errors. Figure 6 shows that the correlation coefficients obtained with System A tend to be higher than those obtained with System B. Figure 7 shows that the r.m.s. errors of System A are smaller than those of System B. Figures 6 and 7 show that System A had higher correlation coefficients and smaller r.m.s. errors than System B, although there were no differences between day effects, as shown in Tables 4 and 5.

The differences between the correlation coefficients and the r.m.s. errors of the two systems were significant $(\mathrm{p}<0.05)$. The differences in these results may depend on the factors affecting threshold have found effects of contact force, contact area, and the presence of surround. The reason of this seems to be considered that Japanese vibrometers do not control the push force, contact force and surrounding, and the acceleration of the threshold may depend on the push conditions of the finger. These factors may affect the difference in the standard deviations of the measured vibrotactile thresholds of the two systems.

Given the vibrotactile threshold values and repeatability of the two systems, it is possible that in the present experiment, the variability in contact force contributed to greater variability in the threshold values obtained with

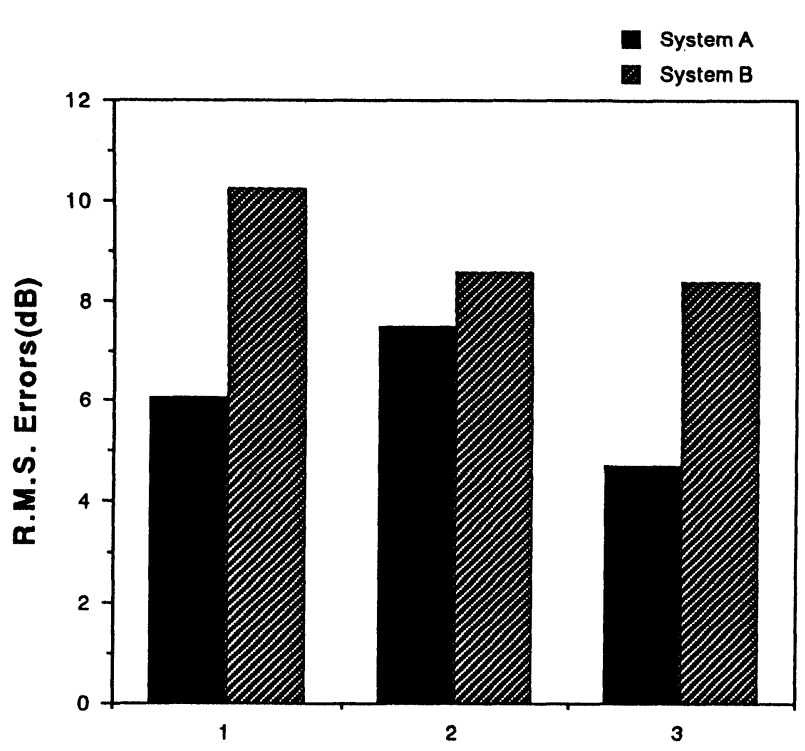

R.M.S. Errors(1:1v2; 2:1v3; 3:2v3)

Fig. 7. The r.m.s. errors between System $A$ and System $B$ There was significant difference $(p<0.05)$ between the two systems.

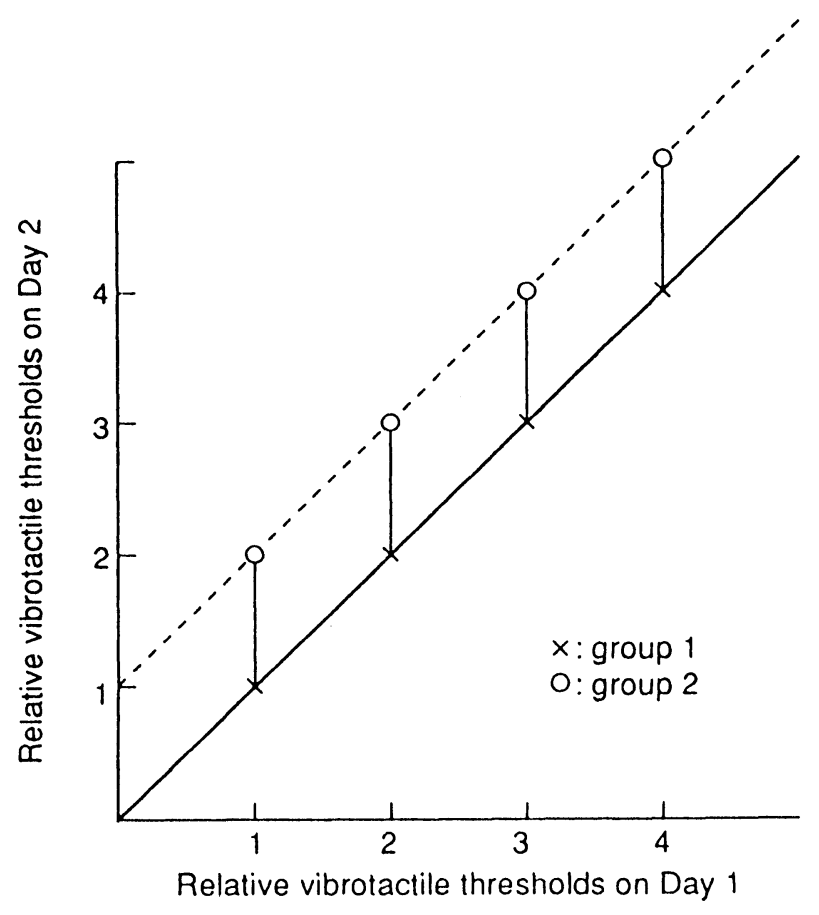

Fig. 8. Use of correlation coefficient and r.m.s. errors to quantify repeatability

System A (ISO-type equipment) than in those obtained with System B (Japanese equipment). 


\section{Vibrotactile Measurement Equipment Conditions Must be Considered in relation to the Vibrotactile Threshold Measurement Equipment used in Japan}

In this study, two different systems (a system satisfies draft of International Standard, System A and a system manufactured by a Japanese company, System B) were used to measure the vibrotactile thresholds at the fingertips. The results obtained clearly showed that the ISO-type equipment showed higher repeatability than the Japanese equipment, and that it also had higher correlation coefficients and smaller r.m.s. errors than the Japanese equipment. The results of this study, as well as of other studies ${ }^{19}$, it clearly indicate that all vibrotactile threshold determinations should consider the frequency of vibration, the area of contact, the conditions surrounding the contact area, the contact force, the push force, and the finger temperature.

Although the ISO/CD 13091 system measures vibrotactile thresholds using three kinds of Mechanoreceptors, SA I (4 $\mathrm{Hz})$, FA I ( $25 \mathrm{~Hz})$, and FA II $(125 \mathrm{~Hz})$, and the Japanese system measures vibrotactile thresholds using only the FA II $(63,125$, and $250 \mathrm{~Hz})$ mecanoreceptor to measure frequency, the vibrotactile measurement equipment conditions adopt at FA I $(31.5 \mathrm{~Hz})$ and FA II $(125 \mathrm{~Hz})$. Although very low frequencies $(<10 \mathrm{~Hz})$ are believed to result in stimulation of SA I mechanoreceptors, this condition neglected the SA I (4 Hz) mechanoreceptor measurement because a stimulation of $4 \mathrm{~Hz}$ makes it very difficult to control the probe on the vibrator. There are also rare data of the effects of the SA I mechanoreceptor after hand-transmitted vibration exposure.

Frequencies below approximately $65 \mathrm{~Hz}$ are believed to stimulate Meissner's corpuscles, while frequencies above 45 $\mathrm{Hz}$ are believed to stimulate Pacinian corpuscles ${ }^{9,10,28)}$. It is believed that measurements should be taken between $20 \mathrm{~Hz}$ and $40 \mathrm{~Hz}$ to assess Meissner's corpuscles and between 80 $\mathrm{Hz}$ and $250 \mathrm{~Hz}$ to assess Pacinian corpuscles. In the context of screening workers exposed to vibrations, some results show that thresholds obtained for Pacinian corpuscles are raised by vibration exposure before those obtained for Meissner's corpuscles and SA mecanoreceptors ${ }^{2}$. Therefore, the recommended frequencies were $31.5 \mathrm{~Hz}$ and $125 \mathrm{~Hz}$ given the time contraints inherent in vibrotactile measurement, since these are the center frequencies of the octave bands in these ranges.

There are also no data on the effects with surround of small contact force and pushing force of ISO/CD 13091, as shown in Table 1, after hand-transmitted vibration exposure.
Table 7. The vibrotactile measurement equipment conditions must be thought when considering the vibrotactile threshold measurement equipment in Japan

\begin{tabular}{lc}
\hline \multicolumn{1}{c}{ Contents } & Recommendation \\
\hline Mechanoreceptor & FA I, FA II \\
Frequency $(\mathrm{Hz})$ & $31.5,125 \mathrm{~Hz}$ \\
Measurement method & Automatic \\
Stimulation & intermittent $(20-160 \mathrm{~Hz})$ \\
Support & full length of forearm, hand and \\
fkin temperature & finger, seat with back rest \\
Room temperature & $26-36^{\circ} \mathrm{C}$ \\
Contact area & $20-30^{\circ} \mathrm{C}$ \\
Probe contact force & 6 mm diameter \\
Surround & $1 \mathrm{~N}$ \\
Finger push force & 10 mm diameter \\
Measurement algorithm & $2 \mathrm{~N}$ \\
Calibration & up-down method \\
Safety & mandatory \\
Vibrotactile thresholds report & $\mathrm{ms}^{-2}$ r.m.s. or dB (re: $10^{-6} \mathrm{~ms}^{-2}$ ) \\
\hline
\end{tabular}

Although these conditions are different with ISO/CD 13091, the vibrotactile measurement equipment of Table 7 adopted the conditions from the results of researchers $\left.{ }^{9}, 19\right)$.

Therefore, in this paper, the vibrotactile measurement equipment conditions must be considered in relation to the vibrotactile threshold measurement equipment used in Japan shown in Table 7. In the equipment conditions of this paper adopted the mechanism of the equipment as shown in Figure 1. The other conditions adopted were those of commercially available vibrometers which control contact force, pushing force and provides a surround.

\section{Conclusion}

A comparison of the vibrotactile thresholds obtained with these two systems permits the following conclusions:

1) System B (the Japnese equipment) measured higher mean thresholds than System A (ISO-type equipment), the difference was $4 \mathrm{~dB}$ and the difference between the two systems yield vibrotactile thresholds which were significantly different;

2) System A (ISO-type equipment) shows higher repeatability than System B (the Japanese equipment);

3) The method of determining vibrotactile thresholds which controlled push force, contact force, and surround gave the greater repeatability in this experiment;

4) From the results of this paper, the vibrotactile measurement equipment conditions must be thought 
of when considering the vibrotactile threshold measurement equipment used in Japan are shown.

\section{Appendix - Instructions for subjects-}

The aim of this experiment is to compare vibrotactile thresholds using two different vibrometers. Please take part in the measuring vibrotactile thresholds as the following procedure.

\section{System A}

$<$ Vibrotactile Perception Test>

This is the equipment for measurement of your vibration sensitivity. Before the measurement, the finger temperature of your right hand will be measured. If your finger temperature is higher than $23^{\circ} \mathrm{C}$ the experiment will start. If not, then you must rest to warm up your hand in a room.

\section{Measuring procedure}

1. Please sit down in your most comfortable pose, and put your right arm on your good position.

2. Support your middle finger to contact on the small plastic tip.

3. You must touch carefully looking at the feedback meter become $2 \mathrm{~N}$, because the contact force between finger and probe must be fixed.

4. If the meter become stable, the measurement will start. At the beginning, this vibration is very small amplitude, gradually it is getting higher. You can confirm the vibration with looking at the oscilloscope.

5. Each sending vibration, we will ask you whether you feel or not. You should answer clearly "feel" or "not feel."

6. We will change the vibration amplitude according to your response.

*Please maintain the push force during your measuring.

\section{System $B$}

$<$ Vibrotactile Perception Test>

This is the equipment for measurement of your vibration sensitivity. Before the measurement, the finger temperature of your right hand will be measured. If your finger temperature is higher than $23^{\circ} \mathrm{C}$, the experiment will start. If not, then you must rest to warm up your hand in a room.

\section{Measuring procedure}

1. Please sit down in your most comfortable pose, and put your right arm on the desk.
2. As the following figure, support your middle finger in your good position on the black button.

3. Your task is to touch the button lightly, because the contact force between finger and probe must be fixed.

4. If your finger force become stable, the measurement will start. At the beginning, this vibration is very small amplitude, gradually it is getting higher.

5. Each sending vibration, we will ask you whether you feel or not. You should answer clearly "feel" or "not feel."

6. The same as System A, We will change the vibration amplitude according to your response.

*It is important you maintain to contact the finger without much pressure.

Thank you for taking part in this experiment.

\section{Reference}

1) Griffin MJ (1990) Handbook of human vibration. Academic Press, London.

2) Brammer AJ (1987) Assessment of impaired tactile sensation. Scand J Work Environ Health 13, 380-4.

3) Hayward R, Griffin MJ (1986) Measures of vibrotactile sensitivity in persons exposed to hand-arm vibration. Scand J Work Environ Health 12, 423-7.

4) Jetzer T, Conrad J, Heithoff K (1987) The role of CT scanning and vibrometry testing in the diagnostic evaluation of carpal tunnel syndrome. In: Proceedings of Volvo-IFSSH Conference on the prevention of brachial inhuries and cumulative trauma disorders, Stockholm. 53-7.

5) Lundborg G, Lie-Stenstrom A-K, Sollerman C, Strömberg T, Pyykkö I (1986) Digital vibrogram: a new diagnostic tool for sensory testing in comparison neuropathy. Hand Surg 11A, 693-9.

6) Lundborg G, Sollerman C, Strömberg T, Pyykkö I, Rosen B (1987) A new principle for assessing vibrotactile sense in vibration-induced neuropathy. Scand J Work Environ Health 13, 375-9.

7) Harada N (1978a) Studies on the changes in the vibratory sensation threshold at the fingertip in relation to some physical parameters of exposed vibration. Part 1. A study on the methods of vibration exposure and measurement of the vibratory sensation threshold. Jpn J Hyg 33, 699-705.

8) Harada N (1978b) Studies on the changes in the vibratory sensation threshold at the fingertip in relation 
to some physical parameters of exposed vibration. Part 2. A study on the equal TTS curves of the vibratory sensation and the hygienic allowable limit of portable mechanized tool. Jpn J Hyg 33, 706-17.

9) Harada N, Griffin MJ (1991) Factors influencing vibration sense thresholds used to assess occupational exposure to hand-transmitted vibration. Brit J Ind Med 48, 185-92.

10) Hayward R (1984) Temporary threshold shifts in vibrotactile sensitivity: effects of vibration duration, intensity, and frequency. In: Proceedings of U.K. informal group meeting on human response to vibration, Heriot-Watt University, Edinburgh, 21-22 September. 36-46.

11) Maeda S (1991) Comparison of the effects of handtransmitted continuous vibration and shock vibration on temporary threshold shifts in fingertip vibratory sensation. In: Proceedings of the Anglo-French vibration meeting and the United Kingdom informal group meeting on human response to vibration, H.S.E., Buxton, 25-27 September. 40-56.

12) Maeda $S$, Kume $Y$ (1987) Temporary threshold shift on finger-tip vibratory sensation induced by exposure to octave band vibration. J Jpn Ind Manage Associ 38, 243-8.

13) Maeda $S$, Kume $Y$ (1989) Temporary threshold shift on finger-tip vibratory sensation induced by exposure to spectrum vibration. J Jpn Ind Manage Associ 40, 336-42.

14) Maeda S, Kume $Y$ (1991) Temporary threshold shift on finger-tip vibratory sensation induced by exposure to intermittent vibration (on the exposure-equivalent rule). J Jpn Ind Manage Associ 42, 105-11.

15) Malinskaya NN, Filin AP, Shkarinov LN (1964) Problem of occupational hygiene in operating mechanical tools. Vestnik Academy Med Sci, USSR, 19, 31-6.

16) Nishiyama $K$, Watanabe $S$ (1981) Temporary threshold shift of vibratory sensation after clasping a vibrating handle. Int Arc Occup Environ Health 49, 21-3.

17) Radzyukevich TM (1969) Interrelation of temporary and permanent shifts of vibration and pain sensitivity threshold under the effect of local vibration. Gigiena Truda i Professional'nye Zabolevanija 14, 20-3.

18) Taoda K (1991) Temporary threshold shift of vibratory sensation (TTSv) induced by the composite band vibration exposure. J Shiga Univ Med Sci 6, 117-26.

19) Maeda S, Griffin MJ (1994) A comparison of vibrotactile thresholds on the finger obtained with different equipment. Ergonomics 37, 1391-406.

20) International Organization for Standardization (1995) Measurement and interpretation of vibrotactile perception thresholds at the fingertips for the assessment of sensory nerve function, ISO/CD 13091 Working Draft.

21) Maeda $S$ (1991) A comparison of measuring equipment and measuring algorithm for vibrotactile thresholds on the fingers. In: Proceedings of the United Kingdom informal group meeting on human response to vibration, ISVR, Southampton, England, September 28-30.

22) Maeda $S$ (1994) A comparison of vibration acceleration magnitude obtained with different vibrotactile threshold measuring equipment. In: Proceedings of the Japan informal group meeting on human response to vibration, NIIH, Kawasaki, Japan, July 1-3.

23) Maeda S, Griffin MJ (1995) A comparison of vibrotactile thresholds on the finger obtained with different algorithms. In: Stockholm workshop 94 Hand-arm vibration syndrome: diagnostics and quantitative relationships to exposure, Arbete och Halsa. eds. by Gemne G, Brammer AJ, Hagberg M, Lundstrom R, Nilsson T, 85-95.

24) British Standards Institution (1986) British Standard Specification for pure tone air conduction threshold audiometry for hearing conservation purposes, BS 6655.

25) International Organization for Standardization (1983) Acoustics-pure tone air conduction threshold audiometry for hearing conservation purposes, ISO 6189.

26) Wetherill GB, Levitt H (1965) Sequential estimation of points on a psychometric function, $\mathrm{Br} \mathrm{J}$ Math Statist Psychol 18, 1-10.

27) Lindsell CJ (1995) Repeatability of simultaneous finger systolic blood pressure measurements on all five fingers. In: Proceedings of the United Kingdom informal group meeting on human response to vibration, Silsoe Research Institute, Wrest Park, Silsoe, September 18-20.

28) Brammer AJ, Piercy JE (1991) Measuring vibrotactile perception thresholds at the fingertips of power-tool operators. In: Proceedings of the Anglo-French vibration meeting and the United Kingdom informal group meeting on human response to vibration, H.S.E., Buxton, 25-27 September. 72-79. 